\title{
As tecnologias vestíveis de moda e a relação entre humano e não- humano
}

The wearable technologies of fashion and the relationship between human and nonhuman

\section{Patrícia Sayuri Saga Kitamura Marini} Mestranda em Têxtil e Moda na Escola de Artes, Ciências e Humanidades da Universidade de São Paulo patricia_kitamura@yahoo.com.br 


\section{As tecnologias vestíveis de moda e a relação entre humano e não- humano \\ The wearable technologies of fashion and the relationship between human and nonhuman}

Patrícia Sayuri Saga Kitamura Marini

\section{Resumo}

$\mathrm{O}$ artigo aborda a afinidade das tecnologias vestíveis de moda em relação ao atual contexto tecnológico, no qual a atuação não-humana torna-se cada vez mais ativa. A concepção da internet das coisas e o desenvolvimento da comunicação ubíqua, pervasiva e senciente expõem uma visão favorável aos wearable technologies. Autores como Bruno Latour, Giselle Beiguelman e André Lemos apontam para um tratamento simétrico das dualidades modernas: físico e virtual, homem e máquina, natureza e cultura, enfim, humano e não-humano. Trata-se de uma corrente de pensamento que propõe a combinação dos polos dualistas, reconhecendo o processo de hibridização.

Palavras- chave: tecnologia; vestível; moda.

\begin{abstract}
The article discusses the affinity of wearable technologies of fashion in relation to the current technological context in which the non-human activity becomes increasingly active. The conception of the internet of things and the development of ubiquitous, pervasive and sentient communication expose a favorable view to wearable technologies. Authors such as Bruno Latour, Giselle Beiguelman and André Lemos point to a symmetrical treatment of modern dualities: physical and virtual, man and machine, nature and culture, in short, human and nonhuman. This is a current of thought that suggests the combination of dualistic poles, recognizing the hybridization process.
\end{abstract}

Keywords: technology; wearable; fashion. 


\section{Introdução}

De acordo com Avelar (2009, p. 27), a moda compreende em vestir "novas ideias que refletem novos paradigmas". Uma das novas visões contemporâneas aborda a possibilidade de um ambiente interativo, no qual objetos trocam informações e executam tarefas sem a necessidade da interferência humana. Trata-se da perspectiva da internet das coisas que possibilita a atuação não-humana de forma independente dos comandos humanos. Dentro desse contexto, surgem a computação e a comunicação ubíqua, pervasiva e senciente. O caráter ubíquo abrange a instauração de uma tecnologia presente em qualquer lugar. "O usuário não vai mais ao ponto da rede. A rede é ubíqua, envolvendo o usuário em ambiente de acesso" (Lemos, 2004, p. 29). Assim, ao se difundir, a tecnologia torna-se parte integrante do cotidiano, ou seja, pervasiva. Já a característica senciente trata da competência dos aparatos tecnológicos de perceberem e responderem ao ambiente. É na capacidade dos objetos de produzir funcionalidades eficazes que o contexto da internet das coisas almeja uma atuação não-humana de forma autônoma. Por esse motivo, como intermediadora da relação do homem com um espaço cada vez mais interativo, as expectativas das tecnologias vestíveis ampliam de forma significativa.

Cada vez mais, os elementos não-humanos tornam-se parte integrante da vida contemporânea, multiplicando-se ao nosso redor com uma rapidez alucinante. McLuhan (2007) aborda os meios de comunicação, incluindo o vestuário, como uma extensão do indivíduo. Porém, para efetivar essa extensão é necessário adotar uma visão que não coloque em oposição o homem e a tecnologia (Lemos, 2013). Nesse sentido, Latour (2013) expõe que a purificação e a separação das dualidades oferecem uma visão limitada, unidirecional e assimétrica. Por esse motivo, Latour (ibid.) propõe um pensamento simétrico. Assim, a relação de oposição entre o humano e o não-humano é questionada, tendo a purificação desmistificada diante o atual cenário tecnológico. Beiguelman (2014) comenta que não faz mais sentido a frase, "o fim do analógico", uma vez que a coexistência do físico e do virtual é vivenciado todos os dias. Da mesma forma, Sibilia (2015) coloca que:

Estão em decomposição os antigos pares de oposições dicotômicas [...] que conformaram a perspectiva dialética na tradição ocidental. Agora não há mais uma linha divisória que separe nitidamente ambos os termos desses pares 
[...]. Onde impera a lógica digital, as variações possíveis excedem os dois integrantes do par dialético, de modo que nesse novo regime as possibilidades combinatórias são infinitas. (Sibilia, 2015, p. 217).

As infinitas combinações que a autora refere é interpretado por Latour (2013) como os inúmeros híbridos que surgem desde o processo de modernização. Dentro dessa linha de pensamento, o reconhecimento dos híbridos é fundamental. Por isso, a hibridização será explanado com maiores detalhes no presente artigo. Mas, primeiramente é necessário adentrar nos conceitos sobre as tecnologias vestíveis de moda.

\title{
2. Tecnologias vestíveis
}

A moda adentra no campo das chamadas tecnologias vestíveis ao agregar um componente computacional na roupa. Existem diversas denominações como computador vestível (ou wearable computer), wearcomp e tecnologia vestível (ou wearable technology). Já Seymour (2008) criou o termo fashionable technology, em 2000, e que se refere à intersecção do design, da moda, da ciência e da tecnologia. Segundo Donati (2004), a tecnologia vestível ou wearable deve incorporar o espaço pessoal de quem veste sem limitar seus movimentos corporais, além de executar algum tipo de "performance computacional" no âmbito artístico ou funcional.

\begin{abstract}
Os wearable computers (ou wearcomps) são aparatos tecnológicos que congregam desde elementos computadorizados inseridos nas tramas dos tecidos até objetos de comunicação acoplados ao corpo por meio das roupas. De acordo com Steve Mann, um dos mais importantes especialistas nessa área, os wearcomps são acoplados no corpo do indivíduo e atuam de forma interativa com ele. Podem executar uma tarefa enquanto a pessoa que os veste atua em outra. [...] Os wearcomps se valem da funcionalidade dos computadores e ainda possuem interconectividade com a pessoa que os vestem. (Avelar, 2009, p. 148).
\end{abstract}

Para a autora, a compreensão de wearable abrange tanto os de suporte têxtil (roupa) quanto os aparatos de estrutura rígida. Exemplos de tecnologias vestíveis produzidas com materiais duros são o Google Glass e o Android Wear (o smartwatch ou "relógio inteligente" que atua em conjunto com o smartphone Android). Trata-se de dispositivos móveis de grandes corporações de informática, telecomunicações e esporte. As tecnologias vestíveis fazem parte tanto da computação quanto da comunicação móvel devido à suas conexões com os corpos em movimento. "O dispositivo vestível, ao ser elaborado de maneira integrada com a própria movimentação do usuário, insere- 
se nas suas atividades diárias numa relação estabelecida pela proximidade e pelo contato físico" (Donati, 2004, p. 96).

No setor esportivo, exemplos de tecnologias vestíveis de estrutura rígida são os aparelhos de monitoramento de corrida como a pulseira da Nike, FuelBand, e a da Adidas, miCoach. Neste último, como o próprio nome sugere, o sistema tecnológico se torna uma espécie de treinador virtual: os dados físicos do corpo são transformados em informações digitais, armazenadas, processadas e analisadas pelos algoritmos (códigos de programação). Convém ressaltar que a Adidas, em parceria com a Polar, lançou uma linha de vestuário nas versões feminina e masculina nas quais é possível acoplar um objeto rígido vestível de monitoramento cardíaco, o miCoach (Hanlon, 2005). Nesse caso, a roupa em si não possui em sua estrutura maleável a capacidade de monitoramento, trata-se apenas de um suporte para o objeto rígido que coleta, armazena e processa os movimentos corporais em dados digitais. Ademais, no site, não é mais possível encontrar, separadamente, a reprodução das imagens dos trajes, sendo estas substituídas por faixas com o aviso de "venda em conjunto com o dispositivo".

Se por um lado, as tecnologias vestíveis de estrutura rígida surgem no mercado advindas de grandes empresas, por outro lado, as que possuem o suporte têxtil estão relacionados às instituições acadêmicas ou pesquisas independentes. Para destacar as tecnologias vestíveis de moda, ou seja, de estrutura têxtil serão apresentados os projetos realizados pela Wearable Experiments (ou, simplesmente, WE:EX). A empresa foi fundada por Ben Moir e Billie Whitehouse na criação de wearables que congregam design, moda e tecnologia.

O projeto Fundawear foi realizado para a empresa de preservativos, Durex. O casal vestido com as tecnologias vestíveis, no caso, roupas íntimas (em duas versões: masculina e feminina) sentem na pele a reprodução do toque do parceiro em qualquer lugar. Primeiramente, o casal realiza um prévio cadastro no sistema do produto para, então, acessar um aplicativo de simulação por meio de seus smartphones. Trata-se de um sistema de conexão sem fio que integra os smartphones e os wearables (roupas íntimas) do casal. Assim, é possível a simulação do movimento de toque (direita para esquerda, vice-versa ou somente em um ponto) e a intensidade (a força aplicada na tela do smartphone é reproduzido no wearable). A figura 1 mostra os dois modelos de 
tecnologias vestíveis comercializadas pela Durexperiment e as ilustrações das interfaces nos smartphones.

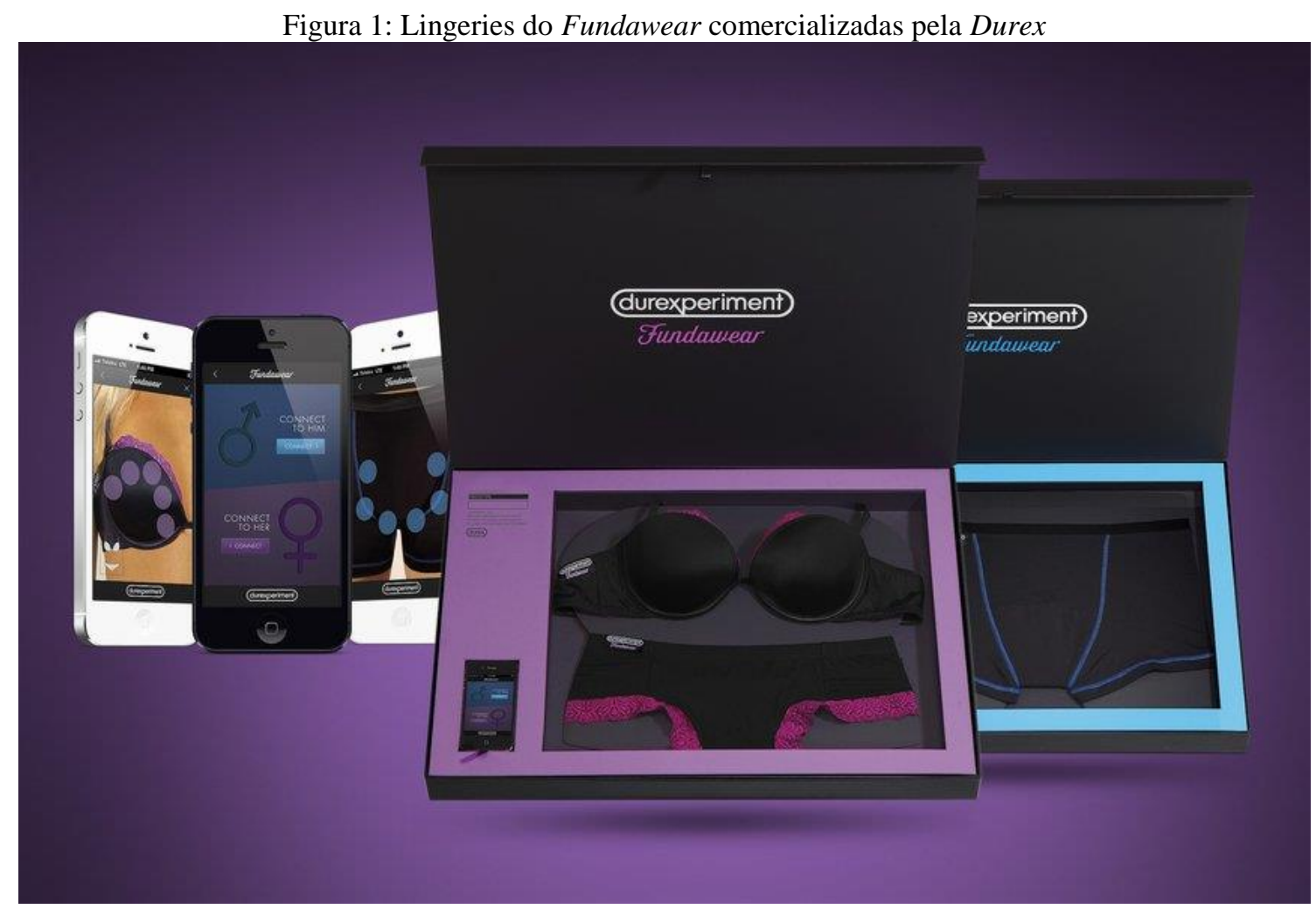

Fonte: http://www.dandad.org/awards/professional/2014/mobile-marketing/23804/durexperimentfundawear/

Outro projeto de reprodução de toque do Wearable Experiments é o Alert Shirt que foi desenvolvido para a Foxtel. Sua intenção é aproximar o telespectador das sensações dos jogadores. O usuário veste o wearable, uma camisa, e conectado ao sistema wireless, por meio do smartphone consegue, por exemplo, sentir o nervosismo do jogador ou o impacto quando ele cai através dos diversos atuadores da tecnologia vestível. Segundo descrito no site do WE:EX, Ben Moir explica que “o Alert Shirt pretende conectar seres humanos através de grandes distâncias e trazer emoções, frustrações e alegrias do jogo ativo para a vida de uma maneira que nós nunca fomos capazes de experimentar antes". As tecnologias vestíveis possibilitam novas experiências entre o corpo e o mundo de conexões wireless (sem fio). Os cinco sentidos do corpo humano não são capazes de perceber as informações digitais que estão em constantes fluxos de movimentações nos espaços urbanos. A incorporação do wearable proporciona uma nova percepção adquirida artificialmente ao corpo. 
A WE:EX também criou outra tecnologia vestível denominado Navigate, um blazer, que auxilia o usuário na localização da cidade, conduzindo-o até o seu destino. A proposta do Navigate é propiciar uma nova experiência de apreciação do cenário urbano, uma vez que não é necessário que ele fique olhando para um mapa na tela do dispositivo. Até o momento, existem três versões do Navigate: Paris, Nova York e Sidney, sendo necessário o cadastro no sistema (software) desenvolvido para o projeto por meio do smarthphone. A indicação de virar à direita ou esquerda é feita por meio de vibrações sutis na roupa do lado direito ou esquerdo, respectivamente. Além disso, a frequência e a intensidade das vibrações indicam instruções específicas. Sendo assim, os diferentes tipos de toques do wearable criam uma linguagem física e particular entre a tecnologia vestível e o usuário.

Como diz Negroponte (1995), a modulação de sinais de processamento a
partir de acessórios "vestíveis" pode construir o body net, uma área pessoal
de comunicação em rede que estabelece conexões por meio do próprio corpo.
Então, o corpo pode ser compreendido como uma entidade tecnologicamente
mediada para operar simultaneamente em diferentes contextos e dimensões
que não se referenciam, como várias "dobras" de existência. Essa realidade é
o resultado de um contínuo processo de conexão de diferentes entidades -
humanas, não humanas, simbólicas, definidas em interações dinâmicas em
um processo de mútua transformação. Os computadores "vestíveis" não
apenas facilitam, mas moldam e transformam algumas atividades físicas e/ou
funções cognitivas ao propor outras maneiras de interação e percepção do
mundo. (Donati, 2005, p. 95-96).

Foram desenvolvidos modelos diferentes de blazer para o Navigate. Na figura 2, Billie Whitehouse, desenvolvedora criativa dos wearables, mostra o detalhe das mangas de sua tecnologia vestível. Esse modelo possui tanto a versão feminina quanto masculina, respectivamente na cor rosa e azul. Ambos possuem uma sinalização por luzes de LED. Na figura 3 é possível observar o circuito de LEDs na parte interna do blazer. Nesse caso, se a tecnologia vestível indicar uma condução para o lado esquerdo, tanto o toque na parte do ombro quanto as luzes da manga, ambas do lado esquerdo, serão ativados. 
Figura 2: Billie Whitehouse mostra as luzes da manga do wearable Navigate

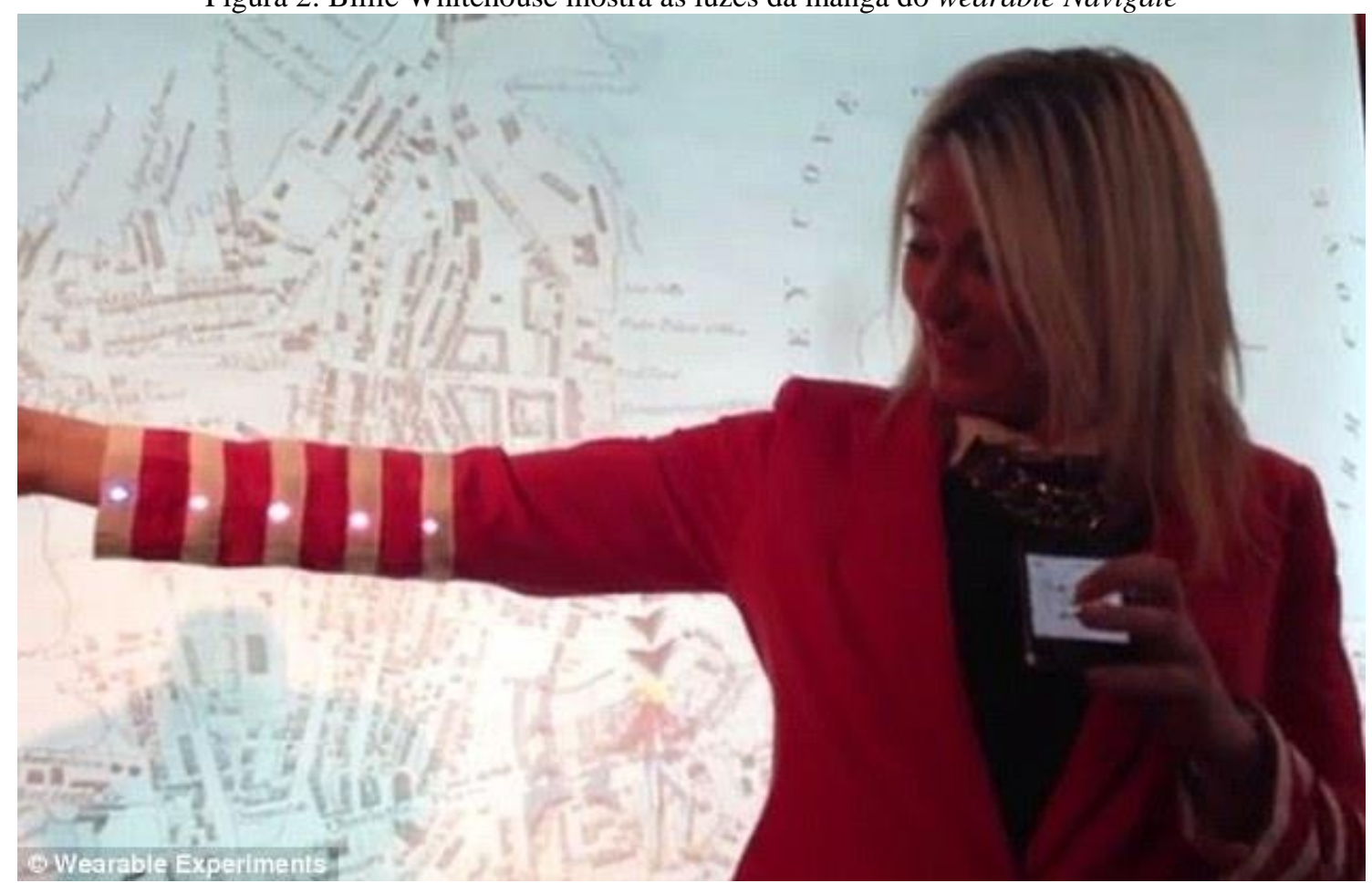

http://www.dailymail.co.uk/sciencetech/article-2502712/Natigate-jacket-GPS-coat-vibrating-sleeves-

point-wearer-right-direction.html

Figura 3: Detalhe da parte interna da manga do wearable Navigate

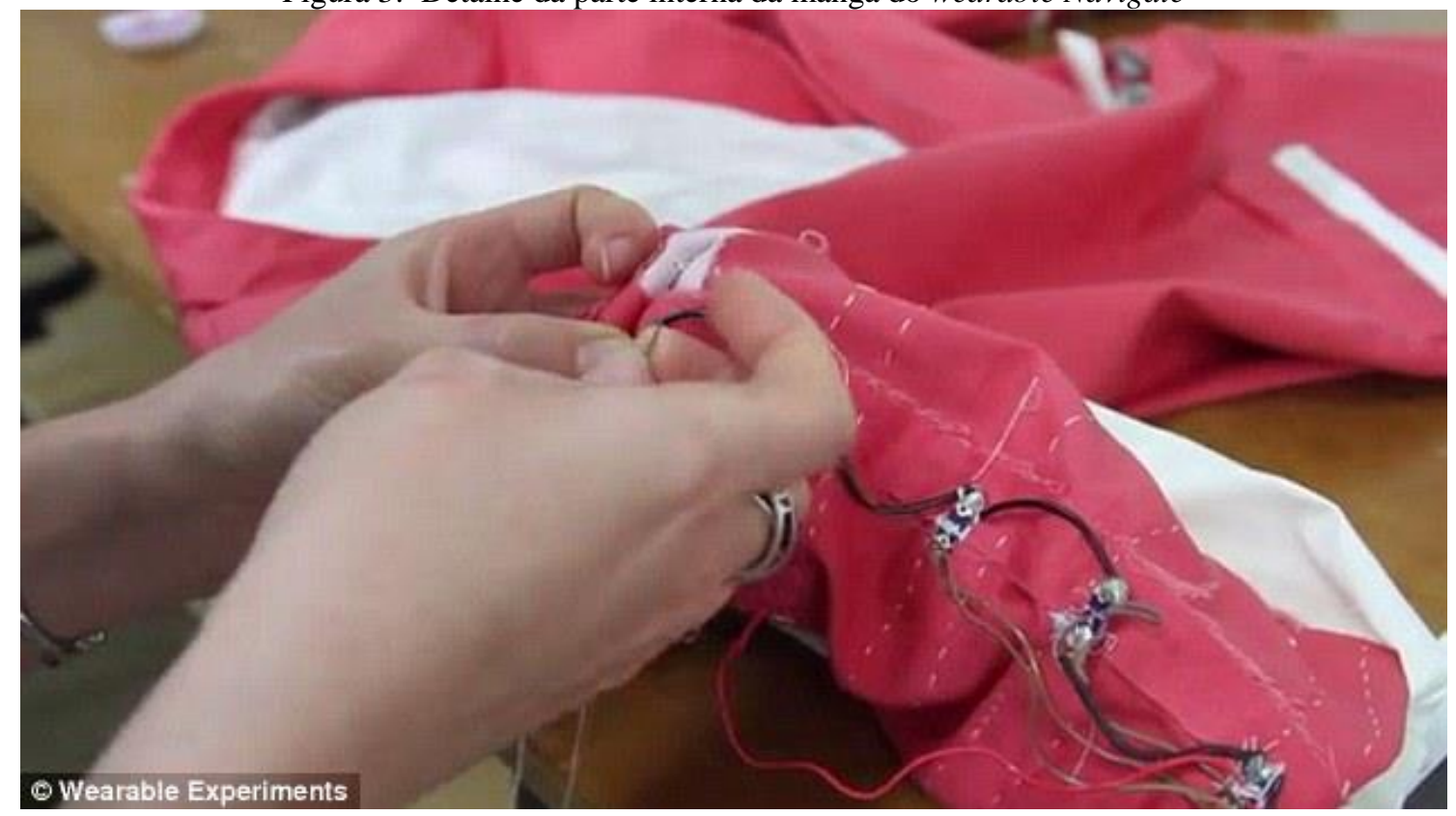

http://www.dailymail.co.uk/sciencetech/article-2502712/Natigate-jacket-GPS-coat-vibrating-sleeves-

point-wearer-right-direction.html 
Os wearables, ao promover a convergência entre moda, design e tecnologia, possibilitam novas maneiras de interação com o usuário e, conseqüentemente, do sujeito com o mundo cada vez mais tomado por dados virtuais. No caso do Navigate, através de uma linguagem específica de toque (intensidade e sequiências de vibrações) o indivíduo mantém seu olhar para apreciar a cidade. Como abordado por Donati (2004), a principal característica do wearable é a liberdade de movimentação tanto do corpo quanto das mãos, permitindo que o usuário realize paralelamente uma tarefa distinta. Nesse ponto, o Navigate é o que mais se aproxima da idealização de uma tecnologia vestível de moda que permite o corpo explorar um espaço tanto físico quanto virtual, proporcionando uma hibridização das sensações naturais do corpo com os dados digitais. Pranav Mistry intitulou sua tecnologia vestível (composta por dispositivos rígidos) de Sixth Sense que evidencia um novo sentido do corpo pautado na virtualidade das tecnologias. A tecnologia vestível traz à tona as dualidades: orgânico e inorgânico, físico e virtual, soft (do tecido) e hard (do circuito eletrônico), corpo e tecnologia, natureza e cultura, enfim, humano e não-humano. Mas, ao invés de separar ou promover uma visão assimétrica (unidirecional), enfatiza o processo de hibridização ou hibridismo. Trata-se da possibilidade de mistura, combinações, aproximações e convergências entre os pares dicotômicos.

\section{Hibridização}

Desde 1980, o termo hibridismo referenciou a sociedade contemporânea, principalmente a latino-americana, para a mistura de estilos; e após a internet seu uso expandiu para designar a convergência das mídias digitais, assim como a interconexão do físico com o virtual (Santaella, 2008). Apesar do uso das palavras hibridismo, hibridização e híbrido em distintas áreas do conhecimento, o sentido comum "é a mistura entre elementos diversos para a formação de um novo elemento composto" (ibid., p. 20).

Dentro do contexto de hibridismo, Sibilia (2015) explana que o Projeto Genoma possibilitou, pela primeira vez, a transferência da informação da biologia humana para a informação virtual do computador. Sendo assim, as manipulações em escala molecular 
"constituem autênticos exemplos de uma hibridização profunda, que mistura matérias orgânicas e inorgânicas" (ibid., p. 88-89).

De acordo com Beiguelman (2011), cada indivíduo contém informações de seus hábitos diários como uma espécie de banco de dados, a autora exemplifica esta afirmação com o interesse das mídias digitais no comportamento individual no ciberespaço para promover o consumo. "Somos, portanto, corpos informacionais que podem não só transportar dados, mas que passam também a ser entendidos como um campo de escaneamento e digitalização de informações" (ibid., p. 43). No contexto das tecnologias vestíveis, o corpo informacional também ganha evidência. Para o projeto Alert Shirt, a Wearable Experiments efetuou uma série de captura de informações corporais que consistia em analisar os movimentos e impactos dos atletas e transformar em fluxos de dados para serem simulados pelo wearable ${ }^{1}$.

A barreira, que anteriormente distanciava os homens e as máquinas, começa a se fragmentar. A tecnologia vestível dentro de um espaço híbrido de atuação significa que “o corpo humano e o computador deixam de trabalhar como máquinas independentes para participar do processo de informação onde dados digitais e físicos operam concomitantemente, permitindo aos usuários afetarem e serem afetados simultanemante por diferentes realidades" (Donati, 2004, p. 96).

\begin{abstract}
A realidade híbrida não se opõe ao físico nem ao virtual, mas antes inclui o virtual dentro do escopo do real. (...) Tecnologias nômades, pequenas interfaces e sensores wireless estão incorporando a realidade virtual nos espaços públicos, não apenas por causa da conexão com a Internet enquanto os usuários estão em movimento, mas porque estas interfaces redefinem a realidade ao promover a emergência de possíveis e distantes realidades dentro do contexto próximo. (De Souza e Silva, 2004, p. 151 apud Donati, 2007, p. 2).
\end{abstract}

No mesmo sentido, Beiguelman (2004) denomina de cibridismo a atual interconexão de redes on e off line. As tecnologias móveis de comunicação sem fio proporcionam redes particulares e ambulantes para os diversos dispositivos existentes nos ambientes: smartphone, tablet, notebook, televisão, videogame, impressora wireless, entre outros. Ao expandir para uma visão dos espaços urbanos: as inúmeras redes dos estabelecimentos, das instituições, residenciais, públicas e móveis compõem um emaranhado imaterial. A invisibilidade desses espaços virtuais junto com a comunicação pervasiva e senciente impedem que sejam notados. Ao contrário, a

\footnotetext{
${ }^{1}$ O vídeo "Alert Shirt Test 2: The Trend Cotchin Endurance Experiment" mostra as etapas do processo de captação dos dados corporais. Disponível em: 〈http://wearableexperiments.com/alert-shirt/>.
} 
presença das redes de comunicação é notada justamente pela sua ausência (por exemplo, quando a bateria acaba ou falta de sinal), pois integram de forma intrínseca diversas atividades do cotidiano. Captados pelos inúmeros dispositivos eletrônicos que nos rodeiam, as informações virtuais garantem o funcionamento da atual vida urbana. Portanto, os espaços tornam-se híbridos ou "cíbridos" (Beiguelman, 2004) ao atuarem de forma conjunta e sem determinismos entre o físico e o virtual, o corpo e a tecnologia, o visível e o invisível, entre outros. Dessa forma, a separação dos distintos dualismos é questionada.

A grande diversidade de aparatos conectados às redes de comunicação, oferece uma sensação de domínio das máquinas em relação ao homem. Porém, Beiguelman (2004) aponta para um fetichismo sobre a "robotização" que pode apontar para um falso senso de obsolescência do corpo diante as novas tecnologias. Ao contrário, para a autora os fluxos de dados digitais são capazes de duplicar a existência através da telepresença. "O termo 'telepresença' foi enunciado pela primeira vez por Minsky² (1980) e apresentou a possibilidade de 'atuação' remota por parte dos usuários a partir de escolhas individuais" (Donati; Prado, 2004, p. 202).

No caso da tecnologia vestível do projeto Alert Shirt da WE:EX ocorreu uma duplicação da existência do jogador profissional através da hibridização dos dados físicos e virtuais. Portanto, o corpo se faz presente através das tecnologias. Nas tecnologias vestíveis, o corpo em movimento ganha uma liberdade ainda mais ampla (para qualquer lugar do planeta), assim como uma presença mediada e potencializada quando ele é hibridizado com os objetos tecnológicos.

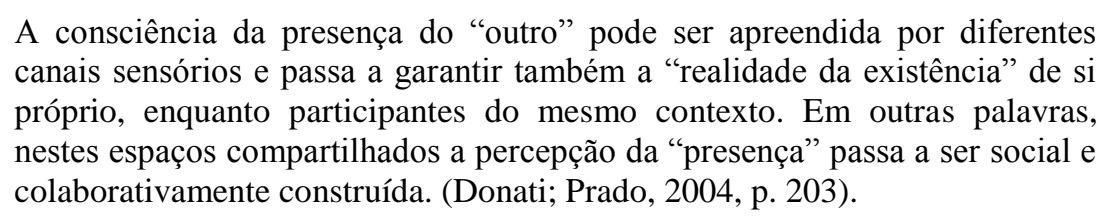

A questão da presença mediada pelo wearable pode ser considerado com maior ênfase no projeto Fundawear, uma vez que o próprio propósito da tecnologia vestível é sentir na pele a presença do parceiro por meio dos dados digitais. "Esta experiência de 'estar presente' é então muito complexa, de caráter subjetivo, ao envolver não apenas características mais formais da própria mídia [...] bem como processos cognitivos e sensórios por parte dos participantes" (Donati; Prado, 2004, p. 204). O lado afetivo do

\footnotetext{
${ }^{2}$ MINSKY, M. Telepresence. Omni Magazine, vol. 2, p. 45-52, 1980.
} 
outro (parceiro), ainda no caso do Fundawear, torna um elemento importante que garante o sucesso na elaboração de uma nova realidade: a crença de que o toque tecnologicamente oferecido é o toque do parceiro. Esse prolongamento do corpo através dos meios de comunicação é o que aponta McLuhan (2007). Avelar (2009, p. 28) ao referenciá-lo, coloca que "nossa sensibilidade em relação à vestimenta é na verdade unificada, pois sentimos também através de nossa pele".

\begin{abstract}
Este hibridismo tem determinado a criação de novos produtos culturais que, por habilitarem simultaneamente os domínios espaciais digital e físico aos usuários, vem potencializando a reconfiguração de relações espaciais e temporais, transformando noções de presença física e possibilidades de atuação. Tecnicamente poderíamos descrever este contexto como ambientes saturados de capacidade computacional e comunicacional que, na maioria das vezes, estão integrados às atividades cotidianas das pessoas. (Donati, 2007, p. $1)$.
\end{abstract}

Lemos (2013) aponta que as ideias de McLuhan foram essenciais para pautar a existência de um meio híbrido. "Um novo meio nunca se soma a um velho, nem deixa o velho em paz. Ele nunca cessa de oprimir os velhos meios, até que encontre para eles novas configurações e posições" (McLuhan, 2007, p. 199). Ainda, ele foi capaz de determinar a importância que a mudança para um novo meio ocasiona na vida humana, pois trata-se de um "novo estalão introduzido em nossas vidas por uma nova tecnologia" (ibid., p. 21). Em um próximo passo, o reconhecimento do processo de hibridização é primordial para o desenvolvimento dos conceitos de Bruno Latour em relação ao humano e não-humano. Antes, porém, é necessário explanar o contexto da internet das coisas, no qual os objetos têm uma atuação muito mais ativa.

\title{
4. Internet das coisas
}

O termo "internet das coisas" ou IoT (abreviação do termo em inglês internet of things) vem ganhando notoriedade no campo tecnológico (Lemos, 2013). O autor ainda coloca que na internet das coisas, os objetos funcionarão de forma independente, ou seja, sem a interferência humana. Assim, não seria mais necessário, por exemplo, fazer a lista de compras e ir ao supermercado (ibid.). Por meio de uma única rede de comunicação sem fio, os objetos das residências seriam capazes de identificar os ítens consumidos e, portanto, enviar uma solicitação de compra para o mercado. "O mundo da internet das coisas já se anuncia no presente, prevendo que todos os objetos do cotidiano estarão conectados às redes e entre si" (Beiguelman, 2013, p. 148). Nesse contexto, eles passam a ter uma nova funcionalidade que Lemos (2013) chama de 
"infocomunicacional". "Os objetos passam a ter capacidades automáticas de processamento de informação, ou seja, de comunicação, acesso e manipulação de bancos de dados. Para que se tenha uma ideia do impacto, hoje há mais objetos conectados à internet do que pessoas no planeta" (ibid., p. 243).

\begin{abstract}
A questão importante para pensar os objetos na cultura digital de uma forma mais ampla é identificar essas tensões a partir do momento em que eles passam a ganhar uma capacidade inédita: a potência infocomunicacional em rede que se traduz em formas de comunicação e de agência à distância. Como compreender que a xícara que agora está na minha mesa muda (como objeto sensível e suas qualidades) ao ganhar poderes infocomunicativos? Imagine que agora, ao ser esvaziada do seu líquido, ela pode solicitar a uma cafeteira em outro lugar a produção de mais café. Esta máquina de café pode me avisar por Twitter ou SMS assim que o novo café estiver pronto, ou pedir ao mercado ao lado para trazer mais grãos de café para trituração. Aqui a xícara é uma xícara, mas é também mais que uma xícara, é uma mídia! (Lemos, 2013, p. 249).
\end{abstract}

“A expressão Internet das Coisas parece ter surgido em 1999 quando, em uma palestra, Kevin Ashton explicava o potencial de uso das etiquetas de radiofrequência (RFID) (Lemos, 2013, p. 255-256). RFID ou radio frequency identification é a tecnologia responsável pelas etiquetas de radiofrequência, nas quais ondas de rádio são capazes de informar dados sobre produtos como, por exemplo, a localização (Lemos, 2004). Ela permite o armazenamento de diversos dados e o rastreamento a longas distâncias. Trata-se de uma informação que é permanentemente ativada e não é "associada a um leitor específico" (Beiguelman, 2011, p. 42). As etiquetas RFID emitem informações por meio de ondas de radiofrequência e são capturadas por qualquer dispositivo que contenha essa tecnologia. Esse acesso aberto das informações propicia a falta de privacidade. Lemos $(2004 ; 2013)$ expõe o caso do uso da etiqueta RFID em uniformes escolares, em que, por meio dos smartphones, os pais verificavam se os filhos estavam, realmente, na escola.

Por meio da utilização das tecnologias RFID, o desenvolvimento da internet das coisas não pode ser pautada sem os avanços da comunicação ubíqua, pervasiva e senciente. "Estamos na era da conexão" (Lemos, 2004, p. 19). Primeiramente, as tecnologias sem fio possibilitaram e potencializaram a computação ubíqua com os atuais aparatos móveis. "O usuário não vai mais ao ponto da rede. A rede é ubíqua, envolvendo o usuário em ambiente de acesso" (ibid., p. 29). A palavra ubiquidade trata da ideia de estar em vários lugares ao mesmo tempo (ibid.). "O caráter pervasivo de ação dos objetos sobre eles mesmos e sobre os humanos na vida cotidiana é que oferece 
a sensação de estarmos diante de objetos vivos, ativos, mediando as ações sociais em busca de objetivos e meta precisos" (Lemos, 2013, p. 258).

\begin{abstract}
A computação ubíqua estabelece no século XXI com o desenvolvimentos das tecnologias móveis ou CCm (computador coletivo móvel) ${ }^{3}$. A computação pervasiva está diretamente ligada à ideia de ubiquiidade, e se caracteriza pela introdução de chips em equipamentos e objetos que passam a trocar informações. (Lemos, 2004, p. 17-18).
\end{abstract}

Dessa forma, a computação senciente "refere-se à possibilidade de interconexão de computadores e objetos através de sensores que passam a se reconhecer de maneira autônoma e a trocar informações" (Lemos, 2004, p. 17-18). "A fase atual da computação ubíqua, dos objetos sencientes, dos computadores pervasivos e do acesso sem fio mostra a emergência da era da conexão e da relação cada vez mais intrínseca entre os espaços físicos da cidade e o espaço virtual das redes telemáticas” (ibid., p. 4041). O processo de hibridização aproximou e integrou as dualidades como orgânico e inorgânico, assim como, físico e virtual.

Apesar de pesquisar e usar o termo, internet das coisas, Lemos (2013) ressalta que a denominação "carece de rigor", pois evidencia claramente o objeto. Nesse caso, o autor apenas adverte para uma possível compreensão equivocada que priorize a tecnologia em detrimento do humano. Como já abordado, o processo de hibridização estabelece a combinação (mistura) de elementos distintos. Portanto, trata-se de uma rede não hierarquizada e híbrida de pessoas e de objetos.

\begin{abstract}
Notemos, em primeiro lugar, não há uma "internet das coisas", nem uma “internet das pessoas". Só há híbridos, na internet ou em qualquer outra rede sociotécnica. Para compreendermos o fenômeno técnico devemos evitar definitivamente a perspectiva essencialista que insista na separação entre sujeito e objeto. O que está sendo chamado de "internet das coisas" é uma nova reconfiguração da rede internet, na qual objetos (reais e virtuais, ou seja, concretos ou digitalizados) trocam informações sem um usuário humano dirigindo diretamente o processo. (Lemos, 2013, p. 242).
\end{abstract}

Nesse ponto, a separação entre esses elementos impede uma possível interrelação que pauta o presente artigo. A atuação autônoma dos objetos na internet das coisas não deve impor um falso sentimento de determinismo tecnológico (Beiguelman, 2004; Lemos, 2013). Ao evidenciar a presença maciça dos híbridos, Latour (2013) proporciona uma visão que inclui a importância tanto dos homens quanto das

\footnotetext{
3 Segundo Lemos (2004), a primeira fase da microinformática nos anos 70-80 caracteriza-se pelo surgimento do PC (personal computer), já a segunda fase nos anos 90 surgem os CC (computador coletivo) com a popularização da internet.
} 
tecnologias. O tópico seguinte oferece um detalhamento de suas ideias que estabelecem uma nova relação entre humanos e não-humanos.

\section{Humano e não-humano:}

O atual panorama tecnológico enfatiza a formação de um coletivo dinâmico e ativo entre as redes humanas, não-humanas e lugares (Lemos, 2004). Latour (2013) denomina de redes socio-técnicas. Como já abordado, a internet das coisas destaca a atuação desse coletivo. A respeito de uma nova proposta, no qual a dualidade é substituída pelo reconhecimento da hibridização, Beiguelman (2011, p. 44) comenta que o "expoente dessa corrente de pensamento é o filósofo e antropólogo francês Bruno Latour. Ele reflete sobre o caráter híbrido da nossa contemporaneidade, mediada pela experiência de objetos e situações que são uma mistura de elementos da natureza e da cultura".

De acordo com Latour (2013, p. 57), há muito tempo ocorre uma proliferação de híbridos como "monstros da primeira, da segunda, da terceira revolução industrial". Para o autor, na medida em que o processo de modernização foi criando os híbridos, eles foram purificados como pertencentes a um dos lados das dualidades modernas. "Os híbridos são tão numerosos que ninguém mais entende como absorvê-los na antiga terra prometida na modernidade" (ibid., p. 130). Sendo assim, "de forma a continuar o pensamento de McLuhan, devemos tentar abolir essa falsa separação para que possamos pensar os eventos em sua complexidade, para além da polarização "physis" - "techné", "sujeito" - "objeto", "natureza" - "sociedade"” (Lemos, 2013, p. 172-173). "É errado pensar em tecnologia e sociedade como esferas separadas influenciando-se: tecnologia e sociedade são mutuamente constitutivas" (Mackenzie; Wajcman ${ }^{4}, 1999$ apud Primo, 2012, p. 626).

Sibilia (2015) aponta para a sensação de vertigem que a interferência técnocientífica causa nos dias de hoje. A autora denomina de evolução pós-biológica, no qual os limites entre as dualidades são constantemente questionadas na área médica. Beiguelman (2011) explana com a biomimética: processo em que os parâmetros da natureza são observados e levados para a indústria na criação de novos materiais. A

\footnotetext{
${ }^{4}$ MACKENZIE, Donald; WAJCMAN, Judy. Introductory Essay: The Social Shaping of Technology. In: (Orgs). The Social Shaping of Technology. Maidenhead: Open University Press, 1999.
} 
autora também apresenta as modificações genéticas feitas em grande parte das frutas e verduras que são consumidas e regularizadas como naturais. A própria cultura é um elemento não-humano, mas que é apreendido pelo homem tornando-se parte inseparável dele. O próprio ato de vestir é um elemento não-humano que foi culturalmente colocado para encobrir o corpo nu. A separação e a purificação dos polos, natureza e cultura, tornam frágeis os seus limites.

Assim, o desenvolvimento da atual sociedade aponta que é impossível definir os limites de cada um: homem e máquina, físico e virtual, natureza e cultura, enfim, humano e não-humano. Como é colocado por Donati (2008, p. 55), "o cotidiano de todo indivíduo está repleto de objetos, cujas funções, texturas e formas, determinam maneiras específicas de pegar, carregar, acionar, jogar, e constroem assim práticas que passam a ser recuperadas em outras situações de ressignificação". Não existe aquilo verdadeiramente puro, pelo contrário, trata-se de híbridos que surgem da combinação entre as dualidades modernas. "Este é o paradoxo moderno: se levarmos em consideração os híbridos, estamos apenas diante de mistos de natureza e cultura, se consideramos o trabalho de purificação, estamos diante de uma separação total entre natureza e cultura" (Latour, 2013, p. 35). Nesse sentido, Lemos (2013) manifesta que:

O que caracteriza a modernidade é justamente este paradoxo entre o sonho de purificação dos domínios humano e não-humano e a proliferação inesgotável de híbridos "sócio-técnico-naturais" que insistem em atravessar as fronteiras imaginárias entre natureza, sociedade, ciência, mercado, cultura etc. (Lemos, 2013, p. 68).

Assim, Latour (2013) propõe em seu livro um ensaio para uma antropologia simétrica, pois a oposição das dualidades evidencia uma assimetria que não mais se sustenta diante do atual contexto tecnológico. "A assimetria entre natureza e cultura torna-se então uma assimetria entre passado e futuro. O passado era a confusão entre as coisas e os homens; o futuro, aquilo que não os confundirá mais" (Latour, 2013, p. 70). Ao adotar um posicionamento simétrico, considerando a convergência e a coexistência das instâncias dualistas, "talvez possamos acolher os híbridos e encontrar um lugar para eles, um nome, uma casa, uma filosofia, uma ontologia e, espero, uma nova constituição" (ibid., p. 55).

Nesse mundo configura-se um novo imaginário, em que as noções de gênero, reinos - vegetal, animal e mineral -, idade e nacionalidade se diluem abrindose em direção a outros modos de ser e existir. Trata-se de uma experiência emergente da subjetividade e da sensibilidade contemporâneas. (Beiguelman, 2011, p. 44-45). 
"A natureza gira, de fato, mas não ao redor do sujeito-sociedade. Ela gira em torno do coletivo produtor de coisas e de homens. O sujeito gira, de fato, mas não em torno da natureza. Ele é obtido a partir do coletivo produtor de homens e coisas" (Latour, 2013, p. 78). Como apontado por Lemos (2013), a posição dialética que separa o humano e o não-humano é posta em questionamento pela nova reconfiguração dos espaços urbanos. "Deixamos que não-humanos façam coisas por nós e fazemos com que humanos façam coisas para não-humano" (ibid., p. 49). Nesse sentido, o autor ainda descreve que o simples fato de avançar em um farol verde sem observar a movimentação da rua é acreditar na mediação não-humana a ponto de colocar a própria vida em risco. O que deve emergir, portanto, é o coletivo humano e não-humano que proporcionam novas mediações.

\section{Considerações Finais}

O desenvolvimento tecnológico aponta para objetos infocomunicacionais atuando de forma independente na visão da internet das coisas. Essa concepção mercadológica, porém, ressalta uma distinção clara e absoluta entre homens e máquinas. Porém, autores como Giselle Beiguelman e André Lemos, ambos pautados nos conceitos de Bruno Latour, apontam para a dissolução de quaisquer dualidades, uma vez que é impossível delimitar seus limites. Da mesma forma que Marshall McLuhan promoveu um impulso ao apontar a existência de um meio híbrido, de acordo com Lemos (2004) devemos continuar esse legado com o pensamento de Latour em uma antropologia simétrica.

$\mathrm{Na}$ atual conjuntura da computação ubíqua, pervasiva e senciente, não existe mais fundamento em distinguir se a comunicação é feita entre humanos ou somente por máquinas ou homem e máquina. O que interessa é observar de forma simétrica, ou seja, não dualista e tentar observar e compreender nas novas mediações proporcionadas por essa nova relação igualitária entre humano e não-humano. A supremacia do homem em relação ao que não é humano torna um discurso que só faz multiplicar "os artigos híbridos que delineiam tramas de ciência, política, economia, direito, religião, técnica, ficção" (Latour, 2013, p. 8).

O caminho que o atual cenário tecnológico percorre só tende a favorecer os wearables em um ambiente interativo. A incorporação do elemento não-humano, a 
roupa, torna as tecnologias vestíveis de moda promissoras. Os wearables de moda são capazes de trazer à tona o híbrido entre as diversas dualidades modernas: orgânico e inorgânico, corpo e tecnologia, físico e virtual, natureza e cultura, enfim, humano e nãohumano. Sendo assim, conceber uma visão simétrica proposta por Latour, Beiguelman e Lemos só contribuirá para novas mediações, associações e experimentações das tecnologias vestíveis de moda.

\section{Artigo recebido em Abril de 2016. Aprovado em Setembro de 2016 DOI:http://dx.doi.org/105965/1982615x09182016117}

\section{Referências}

ADIDAS miCoach. Disponível em: <http://micoach.adidas.com/br>. Acesso em: 23 jul. 2016.

AVELAR, Suzana. Moda: globalização e novas tecnologias. São Paulo: Estação das Letras e Cores, 2009.

BEIGUELMAN, Giselle. Admirável mundo cíbrido. In: ALZAMORA, Geane et al. (Org.). Cultura em fluxo: novas mediações em rede. Belo Horizonte: PUC Minas, 2004, p. 264-281.

. O fim do virtual. seLecT, v. 1, p. 38-47, 2011. Disponível em: https://www.academia.edu/1634076/O_Fim_do_Virtual. Acesso em: 20 dezembro 2014.

Arte pós-virtual: a criação e agenciamento no tempo da Internet das Coisas e da próxima natureza. Cyber-Arte-Cultura: a trama das redes, Espírito Santo, 2013.

DONATI, Luisa Paraguai. Computadores vestíveis: convivências de diferentes espacialidades. Conexão: comunicação e cultura, Caxias do Sul, v. 3, n. 6, p. 93-102, 2004.

O computador como veste-interface: (re)configurando os espaços de atuação. 28/01/2005. 198 f. Tese (Doutorado em Multimeios) - Instituto de Artes, Universidade Estadual de Campinas, Campinas, 2005.

Dispositivos móveis: espaços híbridos de comunicação. In: XXX Congresso Brasileiro de Ciências da Comunicação, Santos, 2007. 
Interfaces multisensoriais: espacialidades híbridas do corpoespaço. Revista FAMECOS, Porto Alegre, n. 37, p. 54-60, 2008.

DONATI, Luisa Paraguai; PRADO, Gilberto. "Wearcomp": dispositivos móveis de presença mediada. In: LEÃO, Lucia (Org.). Derivas: cartografias do ciberespaço. São Paulo: Annablume; Senac, 2004.

HANLON, Mike. Adidas and Polar introduce the world's first completely integrated training system. GizMag, ago. 2005. Disponível em: <http://www.gizmag.com/go/4402/>. Acesso em: 13 jan. 2015.

LATOUR, Bruno. Jamais fomos modernos: ensaio de antropologia simétrica. São Paulo: Editora 34, 2013.

LEMOS, André. Cibercultura e mobilidade: a era da conexão. In: LEÃO, Lucia (Org.). Derivas: cartografias do ciberespaço. São Paulo: Annablume; Senac, 2004. - A comunicação das coisas: teoria ator-rede e cibercultura. São Paulo: Annablume, 2013.

MCLUHAN, Marshall. Os meios de comunicação como extensões do homem. São Paulo: Cultrix, 2007.

NIKE FuelBand. Disponível em: 〈http://www.nike.com/us/en_us/c/nikeplus-fuelband〉. Acesso em: 23 jul. 2016.

PRIMO, Alex. O que há de social nas mídias sociais? Reflexões a partir da Teoria AtorRede. Contemporanea: informação e cultura, v. 10, n. 3, p. 618-641, 2012.

SANTAELLA, Lucia. A ecologia pluralista das mídias. Revista FAMECOS, Porto Alegre, n. 37, p.20-24, 2008.

SEYMOUR, Sabine. Fashionable technology: the intersection of design, fashion, science and technology. Wien: Springer, 2008.

SIBILIA, Paula. O homem pós-orgânico: a alquimia dos corpos e das almas à luz das tecnologias digitais. Rio de Janeiro: Contraponto, 2015.

WEARABLE Experiments. Disponível em: <http://wearableexperiments.com>. Acesso em: 